\title{
Press report
}

$\mathrm{Ir}$ is now virtually certain that President Carter will name Frank Press, a distinguished geophy'sicist from the Massachusetts Instifute of lechnology, as his science adviser and head of the White House Office of Science and Technology Policy (OSTP). Though no official announcement had been made by the end of last week, Press was already at work in the White House, helping to select candidates for other top science posts in the federal government and attending meetings of Carter's senior advisers. Administration sources indicated that a formal announcement was imminent.

The appointment of Press, which was first rumoured a couple of weeks ago, is something of a surprise. Although he is no stranger to the Washington science policy network, he is not generally regarded as part of the inner circle of the scientific establishment. It was, in fact, widely expected that the job would go to Lewis Branscomb, head of research at International Business Machines (IBM), who coordinated a science policy task force for Carter during the campaign. It has been suggested, however, that Branscomb was ruled out hecause several people with IBM connections had already been appointed to top posts in the Carter Administration, a fact which has attracted some criticism.

Press was recommended to Carter by a number of prominent scientists, particularly Defense Secretary Harold
Brown and Jerome Wiesner, President of MIT, and his appointment has generally been greeted with warm approval in the scientific community. An outstanding scientist, he was elected a member of the National Academy of Sciences at the age of 33 . He was Professor of Geophysics at Caltech from 1955 to 1965 and Director of the Seismological Laboratory for much of that time. Since 196.5 he has been Chairman of the Department of Earth and Planetary Sciences at MIT.

Among his credentials for the science adviser post is his wide experience in the science and politics of test ban negotiations. He has long been interested in the problem of identifying the seismic waves from underground nuclear explosions and discriminating them from signals from earthquakes. He was a United States delegate to the test ban conference in Geneva in 1960-62, which paved the way' for the partial Test Ban Treaty in 1963, and he has been a consultant to the Arms Control and Disarmament Association. In 1968 he was a member of the international working party convened by the Stockholm International Peace Research Institute which reopened the question of monitoring underground weapons tests. Since (arter has frequently promised to see a comprehensive test ban agreement with the Sovict Union, Press's experience in such matters is said to have been a strong point in his favour.

Other relevant Washington experi- ence includes a stint on the President's Science Advisory (ommittee (PSAC) from 1961 to 1964. and membership of the National Science Foundation, from 1970) to 1976. He is also (hairman of the National Academy of Sciences' ('ommittee on Scholarly (ommunication with the People's Republic of China, and has travelled extensively in China in recent years.

Even though Press's administrative burden has grown heavier every year, he has continued to make major and distinguished contributions to geophysics. His early work was concerned with seismic wave propagation in the earth's crust and upper mantle. and this eventually resulted in a book Elastic Waves in Lavered Media in collaboration with $M$. Ewing and $W$. Jardetzky. The book had a great influence on the emerging science of seismology. In the 1960s his interests turned to lunar seismology and he was a member of the Apollo team that discovered moonquakes. In the same period he was also encouraging early. US research in earthquake prediction as Chairman of the Karthquake Prediction Panel of the Office of Science and Technology. In the late 1960s he started to work on the problem of inversion of earth data by Monte Carlo methods, and more recently his research has included study of the excitation of the Chandler Wobble by earthquakes. In 1974 he published. with R. Siever, a major geology/ geophysics text Earth.

Colin Norman posals, moreover, are only a foretaste of a comprehensive energy policy which Carter has promised to anveil in midApril.

The budget revisions suggest that the besieged liquid motal fast breeder reactor (I.MFBR) programme is in deep trouble. Carter has recommended that nearly $\$ 200$ million should be taken out of Ford's budget request for the L.MFBR effort next year, a reduction which would still leave $\$ 6.56$ million in the programme, but which would cut spending to bclow this year's level. A statement published last week by the Energy Research and Development Administration (ERDA), which is said to have been Urafted by Schlesinger, announced that the entire L.MFBR programme will be subjected to an intensive review. to "assess the role of I.MFBRs in the nation's energy future. the timing and pace of the breeder programmes and the timing of any decision on whether the breeder would be a viable energy option".

The implications are made clear later in the statement:

The President's energy priorities, as reflected in the revision of ERDA's (fiscal year) 1978 budget request. stress conservation and mearer-term supply technologies. These priorities suggest that past plans for expansion of the LMFBR program may no longer be viable. Furthermore. serious questions have been raised about the LMFBR technology and the structure of the current LMFBR program. The energy potential of this option must be weighed against the safety questions associated with the LMFBR and the dangers of nuclear proliferation from plutonium reprocessing needed by L.MFIBRs.

In particular, the review will focus on ERDA's plans to build a demonstration fast breceler reactor on the (linch River in Tennessec. a project which represents the next major step in the I.MPBR programme in the United States. Construction of the Clinch River plant was scheduled to begin later this year, but it will now be delayed pending the outcome of the review. Conseguently. (arter has suggested that $\$ 8.5$ million be cut from Ford's request for that project alone. No date has been set for completing the review, but it is unlikely that a final decision will be ready in time for inclusion in the energy policy which (arter will unveil in April.

As for solar energy research and development, again. long-term efforts ar: being cut hack to allow more funds to be channelled into programmes likely to produce more immediate results. Aceordingly. Carter has scaled down Ford's budget proposal for construction of a pilot-scale solar thermal gencrating plant, and recommended that the savings be used chiefly to underwrite the costs of producing and testing some 1,300 solar heaters.

The pilot plant project which (arter wants to cut was only given a g()-ahead by the Ford Administration on 7 January. It would entail construction 